\title{
Krankenversicherung
}

\section{Sonderkonditionen für Ärztinnen und Ärzte}

Jeder zweite Schweizer zahlt jährlich über 600 Franken zu viel Krankenkassenprämie. Gehören Sie auch dazu? Unsere Spezialisten überprüfen kostenlos und unverbindlich, wie hoch Ihr Sparpotential ist. Zudem profitieren Sie in den FMH Insurance ServicesRahmenverträgen von bis zu $50 \%$ Rabatt auf den Zusatzversicherungen.

Bestellen Sie mit dem unten stehenden Talon Ihren persönlichen Offertvergleich. Bitte senden Sie uns eine Kopie Ihrer aktuellen Police, damit wir Ihnen ein vergleichbares Angebot berechnen können.

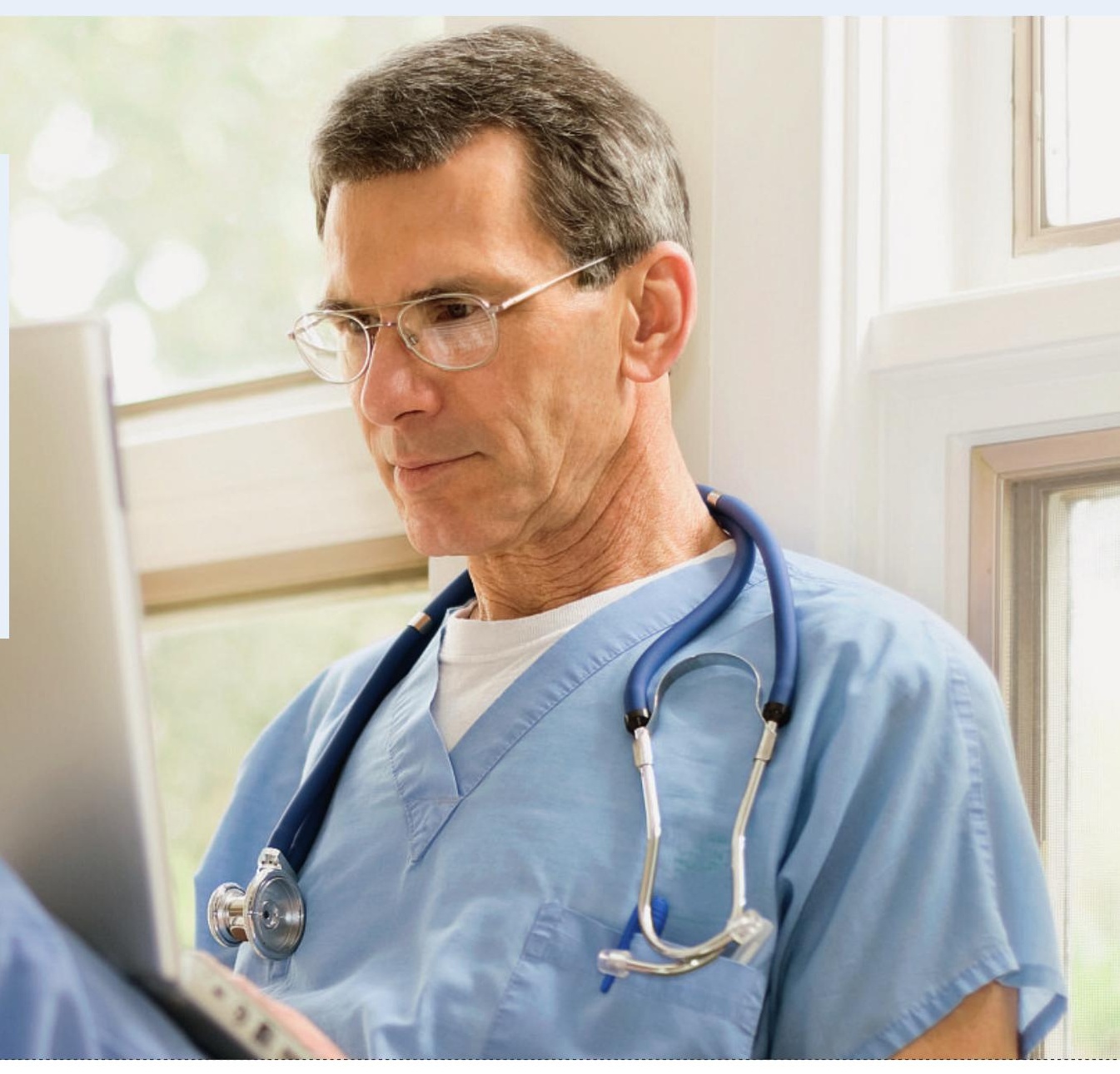

Antworttalon

Bitte einsenden oder per Fax an: 0319595010

Vorname / Name

Adresse

PLZ / Ort

Geburtsdatum

Telefon privat / Geschäft

Beste Zeit für einen Anruf

E-Mail-Adresse

Ja, ich will Krankenkassenprämien sparen! Bitte senden Sie mir eine Offerte.

(bitte aktuelle Policenkopie beilegen)

O Bitte suchen Sie für mich das beste Angebot aus ODER

Ich möchte eine Offerte der folgenden Kasse (max. 2 Offerten)
O Innova
O KPT
O Helsana-Gruppe

Bitte rufen Sie mich für eine persönliche Beratung an.

Ich interessiere mich für:
O Finanz-/Steuerplanung
O Pensionskasse BVG
Säule $3 a$
O Rechtsschutzversicherung
Kapitalanlage
O Berufshaftpflichtversicherung

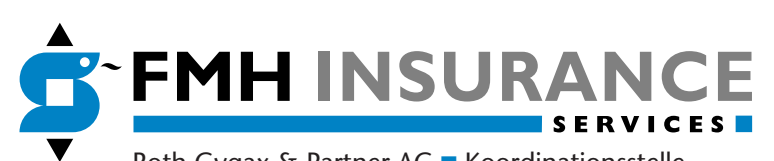

Roth Gygax \& Partner AG — Koordinationsstelle Moosstrasse 2 a 3073 Gümligen

Telefon 0319595000 a Fax 0319595010 mail@fmhinsurance.ch 1 www.fmhinsurance.ch 